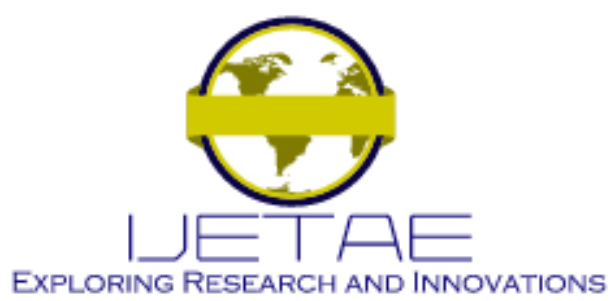

International Journal of Emerging Technology and Advanced Engineering

Website: www.ijetae.com (E-ISSN 2250-2459, Scopus Indexed, ISO 9001:2008 Certified Journal, Volume 11, Issue 08, August 2021)

Manuscript Received: 17 June 2021, Received in Revised form: 05 August 2021, Accepted: 15 August 2021

DOI: 10.46338/ijetae0821_12

\title{
Cluster Formation and Maintenance Techniques for Mobile Adhoc Networks with Improved Quality of Service
}

\author{
Amit Gupta ${ }^{1}$, Mahesh Motwani ${ }^{2}$, J. L. Rana ${ }^{3}$ \\ ${ }^{1}$ Research Scholar, Department of Information Technology, UIT-RGPV, Bhopal (M.P.), India. \\ ${ }^{2}$ Professor, School of Information Technology, UTD-RGPV, Bhopal (M.P.), India. \\ ${ }^{3}$ Advisor, Radharaman Group of Institutes, Bhopal (M.P.), India.
}

\begin{abstract}
In an Adhoc Network, every node is mobile and self-contained. As these networks lack infrastructure, highly adaptive algorithms are required to deal with frequent mobility changes by member nodes as well as Cluster Head (CH) nodes. The weighted clustering algorithms contribute significantly to cluster-based routing. In these algorithms, the selection of cluster heads is the most important task. In weighted clustering methods, the selected $\mathrm{CH}$ did their best to serve the network. However, the $\mathrm{CH}$ may become overloaded due to the arrival of nodes greater than their desired threshold value. In this case, the $\mathrm{CH}$ can become a bottleneck as it is unable to cope with rapidly increasing loads which ultimately degrade the network performance. In this paper, we address three network issues (i) Member Node movement (ii) Cluster head Node movement, and (iii) Overload at the Cluster head node caused due to mobility of nodes. Our proposed method Cluster Formation and Maintenance Techniques for Mobile Adhoc Networks with Improved Quality of Service (CFMIQS) include various adaptive algorithms to provide solutions to deal with these network issues and improve network Quality of Service (QoS). The Simulated Results are compared with the K-means AODV algorithm, the results showed better Packet Delivery Fraction (PDF) and Throughput values.
\end{abstract}

Keywords - Cluster partition, MANET, Primary Cluster head, QoS, Secondary Cluster head

\section{INTRODUCTION}

A Mobile Adhoc Network (MANET) is a decentralized network that consists of self-contained mobile nodes connected by wireless links [1]. The functions of MANET can be performed without the need for any fixed infrastructure. The MANET topology changes dynamically as new nodes join the network and existing nodes leave due to node mobility. The cluster-based concept is used in MANET, to divide the entire network into sub-networks. These sub-networks are interconnected to each other and called Clusters.
Every Cluster in a Network has three types of nodes. (i) Cluster Head $(\mathrm{CH})$ Nodes: They serve as a coordinator in a Cluster and takes major decisions related to network topology and resource allocation. (ii) Member Nodes: They are also called ordinary nodes and only communicate with the $\mathrm{CH}$. (iii) Gateway Nodes: These nodes lie within multiple clusters transmission range. They are used to communicate between nodes from different clusters.

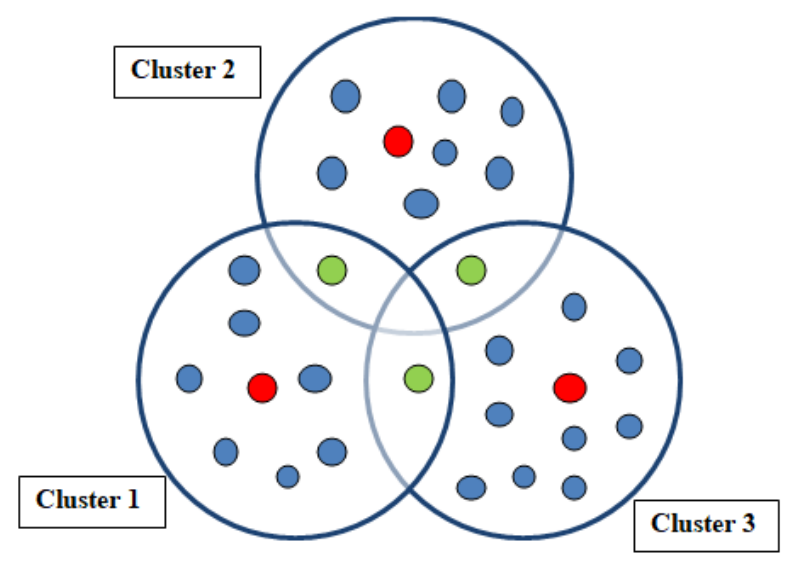

Figure 1. Clustering in MANET

Here, in Figure 1

(Red Color) represents Cluster Head nodes

(Blue Color) represents Member nodes

(Green Color) represents Gateway nodes

The choice of cluster heads is crucial because the network's performance is dependent on its suitability. Cluster heads are chosen based on a variety of node performance factors like Mobility, Energy, Battery Power, etc. from all member nodes of a cluster. 


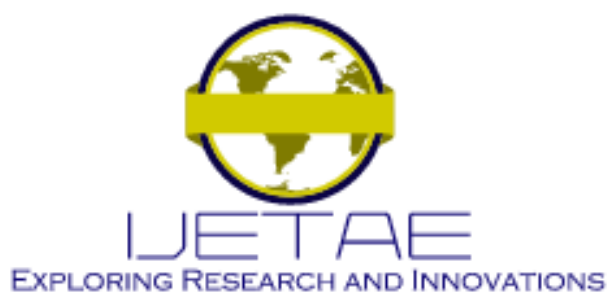

International Journal of Emerging Technology and Advanced Engineering

Website: www.ijetae.com (E-ISSN 2250-2459, Scopus Indexed, ISO 9001:2008 Certified Journal, Volume 11, Issue 08, August 2021)

In this paper, we are dealing with the mobility factor of nodes. In cases, where the member node or cluster head node leaves a cluster and joins another cluster, then reaffiliation will take place [2]. We are dealing with three different network issues considering the mobility of nodes (i) Member Node Movement: Due to the mobile nature of adhoc networks, there is always the possibility that a node will leave or join a cluster. (ii) Cluster head node movement: If a cluster's cluster head leaves, it will require a cluster update if it doesn't hear from any of its members. (iii) Overload at the cluster head: To service the member nodes, a threshold value is set for the cluster head. If this value is exceeded, the overloaded cluster must be partitioned into two parts through a cluster partition procedure. We developed different adaptive algorithms to provide solutions to deal with these network issues. These solutions also lead to the rearrangement of existing clustering structures through cluster maintenance procedures by selecting the best cluster head which ultimately improves the Quality of Service (QoS) of the network.

This paper is organized in the following sections:

Section II summarizes the previous related works. Section III presents the proposed work for three different issues. Section IV represents their Simulation Results. Section V performs the comparison and Result Analysis and finally, Section VI describes the conclusion.

\section{LITERATURE SURVEY}

Various authors have contributed significant research to this field of study. Some of the notable research contributions are related to this field.

B.A.Kumar et al. [3] combine a reactive MANET routing protocol with an energy consumption technique. This method uses K-Means clustering in conjunction with AODV routing to find the shortest route in the network and improves performance through Ant Colony Optimization (ACO). As per the results, this method outperforms the previously reported methods Mobile Agents based Reliable and energy-efficient routing protocol (MAREERP) and Energy Efficient Hybrid Routing Protocol (EE-HRP) in terms of (i) Energy Consumption, (ii) Delay and (iii) Packet Delivery Ratio (PDR).

M.Vijayalakshmi et al. [4] develop a new routing protocol Energy-Aware Multicast Cluster (EAMC) to improve the performance of AODV and Multicast AODV protocols.
The effectiveness of this protocol is measured in terms of (i) Consumption of Energy (ii) Packet Delivery Ratio (PDR) (iii) Loss (iv) Throughput and (v) Average Delay. The results of the NS2 Simulator showed that this protocol outperforms AODV and Multicast AODV and hence it achieves a high level of QoS in MANET.

J.O. Jejeniwa et al. [5] use the new technique Dual Head Cluster Algorithm (DHCA) for MANET which has two cluster heads namely Cluster Head $(\mathrm{CH})$ which works as the Primary Cluster Head and Aggregator Head (AH) which works as the Secondary Cluster Head for inter and intra cluster communication, data aggregation, cluster maintenance, and route management. These heads collectively decrease the end-to-end delay \& re-clustering frequency. Simulation results indicate that the DHCA outperforms conventional clustering protocols in terms of end-to-end latency, network lifetime, and energy conservation.

N. Rajendran et al. [6] proposed a zone division clustering algorithm in which the entire MANET region is partitioned into four equal parts, each of which is referred to as a zone and has a zone head in charge of the cluster heads in that zone. Each node has given a rank based on parameters like memory size, energy consumption speed, residual energy, and transmission speed. The nodes with the highest and second-highest ranks are selected as primary and secondary cluster heads respectively. The intelligent selection of cluster heads improves the cluster and zone's stability; the cluster heads will step down automatically when the residual energy level falls below the threshold value. Their proposed algorithm is tested using the NS2 simulator, and it outperforms existing clustering algorithms Evolutionary Zone Routing Protocol (EZRP) and Efficient Ad-hoc On-demand Multipath Distance Vector routing (EAOMDVR) in terms of cluster formation, packet delivery ratio, on-demand re-clustering, and throughput.

S.Aruna et al. [7] proposed a protocol Security-Based Double Cluster Based Routing Protocol (SD-CBRP) aims to improve service quality while ensuring security. This technique works to provide a Secondary Cluster Head (SCH) for every Primary Cluster Head (PCH). As an outcome, the average end-to-end latency is minimized, and link breakages are prevented by designating double cluster heads. When compared to the weighted cluster-based protocol (CBPMD), the proposed protocol (SD-CBRP) avoids repeated cluster re-affiliation and gives better throughput, delay, and packet delivery ratio. 


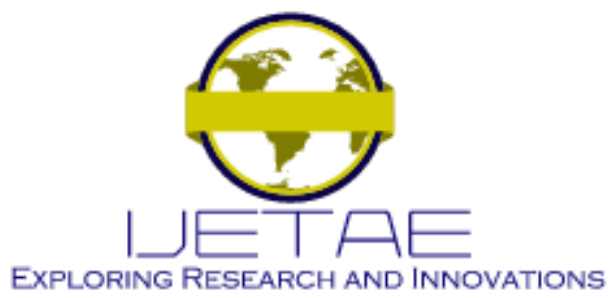

International Journal of Emerging Technology and Advanced Engineering

Website: www.ijetae.com (E-ISSN 2250-2459, Scopus Indexed, ISO 9001:2008 Certified Journal, Volume 11, Issue 08, August 2021)

V.B.Vieu et al. [8] suggested a hybrid algorithm Mobility Prediction-based Weighted Clustering Algorithm using Local cluster-heads election (MPWCA-L) made from two algorithms namely MPWCA for use in prediction and WCA-L for use in the local election process. These algorithms are available on-demand and based on MANET distributed clustering. The suggested algorithm limits the overhead induced by control messages. Simulations results showed that MPWCA-L outperforms the Weighted Clustering Algorithm (WCA) concerning overhead and packet delivery rate and hence provide greater stability and QoS.

K.S.Sowmya et al. [9] proposed a method that is a combination of the Weighted Clustering Algorithm (WCA) \& Ant Colony Optimization (ACO). This paper uses the routing protocol Ad hoc On-Demand Distance Vector (AODV) \& ACO to compare performance parameters such as packet delivery fraction, packet loss, and throughput. To obtain additional routing information, the ACO protocol incorporates path accumulation during the route discovery process in AODV. The results show that the use of ACO improves the performance of AODV in situations with moderate to high mobility and high load.

P.Dixit et al. [10] proposed a Light Weight Efficient Cluster based routing Model (LWECM) that extends the life of cluster heads by reducing cluster heads needless participation in network communication. The refugee node idea is initiated to simplify the maintenance procedure and limit the cluster numbers in the network. By accessing the Burden Factor (BF), a measure of remaining power and node degree, the model ensures a fair distribution of load across cluster heads.

L.Wang et al. [11] proposed a tree-based cluster-centric node mobility algorithm for Cluster Maintenance. The algorithm is based on diameter-2 graphs properties for 2 scenarios (i) Failure of Single-link (ii) Failure of Singlenode. This algorithm is more effective as demonstrated through simulation results than other Degree-based clustering algorithms in terms of mobility and node density.

S.Pathak et al. [12] proposed an Improved Cluster Maintenance Scheme (ICMS) intending to reduce the $\mathrm{CH}$ changes frequency and improves the stability of the cluster. The cluster head's (i) priority and (ii) delayed time factors are considered for choosing a new cluster head in ICMS.
The NS-2 simulated results of ICMS are compared with Incremental Maintenance Scheme (IMS), Cluster-Based Routing Protocol (CBRP), and Least Cluster head Change (LCC) algorithms in terms of overhead in clustering, changes in cluster member, and changes in cluster head. The results prove that ICMS outperforms these compared algorithms.

K.A.Yitayih et al. [13] proposed efficient QoS-aware routing in MANET through Optimal Link State Routing (OLSR) protocol. By taking into account several constraints and a clustering approach that requires less maintenance, MANET nodes can be grouped more efficiently. The authors present a superior Multi-Point Relay (MPR) selection and routing calculation approach that promises to provide effective QoS routing considering all factors such as delay, throughput, overhead, transmission error, and scalability. The Simulation performed on OMNET++ using the INET framework shows that Cluster-based QoS is improved by increasing (i) throughput \& (ii) packet delivery ratio while decreasing the (i) routing load \& (ii) end-to-end delay.

H.G.Kidanu et al. [14] show the formation of a cluster that is based on distance measurement. It constructs clusters based on the distance between the cluster head and the cluster members. In MANET, distance-based clustering is important as it can extend the network's life. The proposed clustering algorithm selects cluster heads at random during runtime, and then nodes that are closer to the cluster head according to their distance are the member of that cluster. The performance parameters (i) residual energy, (ii) distance graph, and (iii) consumed energy from each cluster head are used to analyze the performance of the distance-based clustering approach using NS-2 and MATLAB.

\section{PROPOSED WORK}

The process of cluster formation is always linked to the process of cluster maintenance. The cluster structure must be updated and reformatted regularly. The followings are the network issues due to which cluster maintenance is needed.

(A) Member Node movement

(B) Cluster Head movement

(C) Overload at the Cluster head 


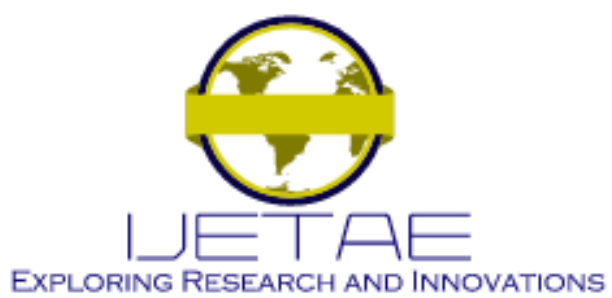

International Journal of Emerging Technology and Advanced Engineering Website: www.ijetae.com (E-ISSN 2250-2459, Scopus Indexed, ISO 9001:2008 Certified Journal, Volume 11, Issue 08, August 2021)

\section{AMember Node movement}

Due to the mobile nature of adhoc networks, there is always a chance that a node can leave its cluster or a node can join a cluster. When a node $n l$ moves out of range of its cluster head $\mathrm{CH} x$, its status changes to "unidentified" and the cluster head $\mathrm{CH} x$ deletes an entry for that node $n 1$ because it is no longer listening to hello message from $n 1$.

If the node $n l$ enters into the coverage area of another cluster head $\mathrm{CH} y$ with the exchange of hello messages, cluster head $\mathrm{CH} y$ came to know that a neighboring node $n 1$ has the status "unidentified", it immediately sends a "join_cluster" to this node $n l$. Node $n l$ responds with "accept_join" and joins the cluster head $\mathrm{CHy}$. Now, node $n 1$ status changes to "identified". If the moving node does not have any cluster head in its neighborhood, then it designates itself as a cluster head.

\section{Algorithm 1: Movement of Member Node}

1. If \{node $n 1$ does not hear from its $\mathrm{CH} x$ \}

2. | Node $n 1$ change its status as "unidentified"

3. If \{node $n 1$ hears from any other $\mathrm{CH} y$ \}

4. $\mathrm{CH} y$ identifies a node $n l$ with the status "unidentified" in the neighborhood

5. CHy sends "join_cluster" to node $n 1$

6. Node $n 1$ replies with "accept join" and become a member of $\mathrm{CH} y$

7. Node $n 1$ change its status as "identified" else

8. Node $n 1$ elects itself as cluster head else

9. No need for cluster update

\section{BCluster Head movement}

A cluster's cluster head can also leave the cluster, requiring a cluster update if it doesn't hear any of its members. When a moving cluster head $\mathrm{CH} x$ moves into another cluster head $\mathrm{CH} y$ coverage area, it withdraws its $\mathrm{CH}$ role and becomes a member of cluster head $\mathrm{CH} y$. If $\mathrm{CH} x$ does not have any cluster head in its neighborhood, it retains its cluster head role, but without any members. As a result of the cluster head's movement, all other member nodes elect a new cluster head for that cluster.
Algorithm 2: Movement of Cluster Head (CH)

1. If $\{\mathrm{CH} x$ receives no communication from any of its

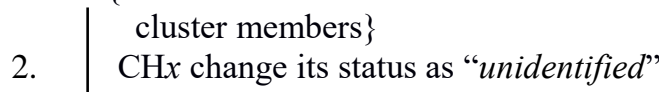

3. If $\{\mathrm{CH} x$ hears from any other $\mathrm{CH} y\}$

4. $\quad \mathrm{CH} y$ identifies a $\mathrm{CH} x$ with the status

$5 . \quad$ "unidentified" in the neighborhood

5. CHy sends "join_cluster" to $\mathrm{CH} x$

6. $\quad \mathrm{CH} x$ replies with "accept_join" and become 7. $\quad \begin{aligned} & \text { a member of } \mathrm{CH} y \\ & \text { Member Node } x \text { change its status as } \\ & \text { "identified" }\end{aligned}$

else

8. $\mathrm{CH} x$ will maintain its status as $\mathrm{CH}$ else

9. No need for cluster update

\section{III. $C$ Overload at the Cluster head}

The clustering structure performs well with uniform traffic at all the cluster heads. Some network issues may occur when a portion of the network experiences high traffic for several reasons. Cluster heads working in these regions may have to work hard to handle the increasing traffic. The performance of the network may degrade due to congestion and packet drop at the cluster heads.

A process of cluster maintenance is required to balance the clusters. A threshold value is set for the cluster head to serve the member nodes. If this value is reached, the overloaded cluster must be partitioned into two parts using a cluster partition process.

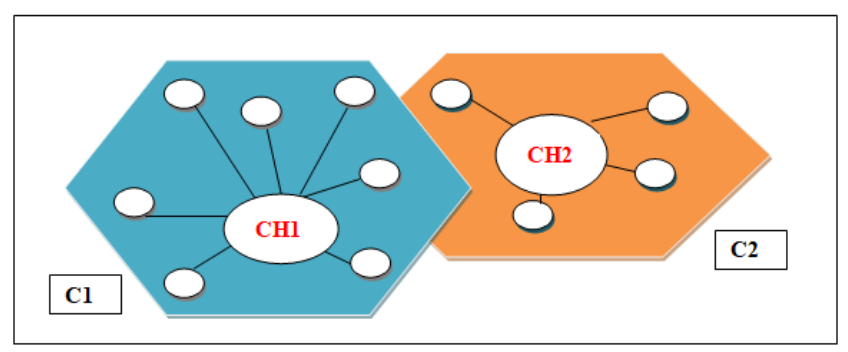

Figure 2. Cluster head CH1 of Cluster C1 is overloaded 


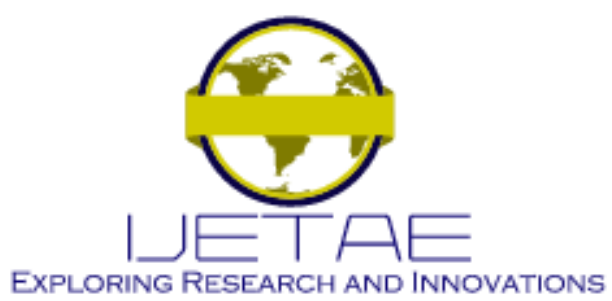

International Journal of Emerging Technology and Advanced Engineering Website: www.ijetae.com (E-ISSN 2250-2459, Scopus Indexed, ISO 9001:2008 Certified Journal, Volume 11, Issue 08, August 2021)

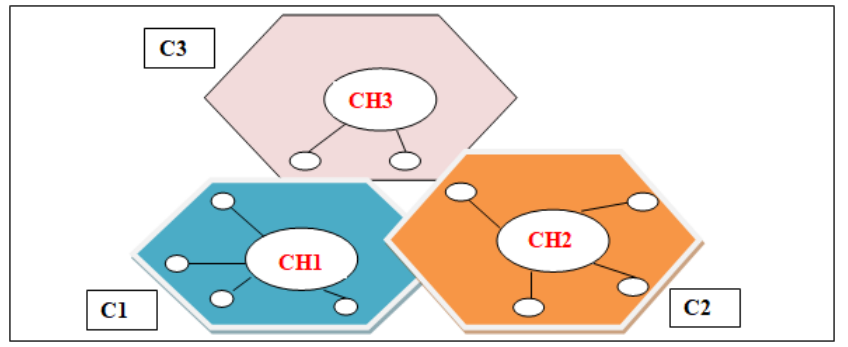

Figure 3. Cluster C1 partitioned into two Clusters C1 and C3

As shown in Figure 2 and Figure 3, the cluster may be partitioned into two parts. We use the concept of weighted metrics to select the newborn or secondary cluster head. In this approach, each cluster head node continuously keeps tracking the numbers of members associated with it. The $\mathrm{CH}$ sends out a Cluster Partitioning message when this value exceeds the predefined threshold value. After receiving this Cluster Partitioning message all the members of the cluster came to know that the $\mathrm{CH}$ is overloaded and cluster partition is about to happen. Primary $\mathrm{CH}$ helps to find out the most suitable node from its member list to serve as the cluster head of the newborn cluster. $\mathrm{CH}$ holds all the information about its members and calculates the Robustness Factor for all members. The Robustness Factor is the weighted sum of the node's important parameters.

These parameters include:

- Distance from Primary $\mathrm{CH}\left(\mathrm{dCH} 1_{\mathrm{n}}\right)$

- Mobility of node $\left(\mathrm{M}_{\mathrm{n}}\right)$

\section{Distance from Primary $\mathrm{CH}\left(\mathrm{dCH} 1_{n}\right)$ :}

When the $\mathrm{CH}$ becomes overloaded it sends the Cluster Partitioning message to its entire members. $\mathrm{CH}$ calculates its distance from all the other members [2]. This can be discovered by contacting the $\mathrm{CH}$ coordinator as well as members.

$$
\mathrm{dCH} 1_{\mathrm{n}}=\sqrt{\left(\mathrm{X}_{\mathrm{CH} 1}-\mathrm{X}_{\mathrm{n}}\right)^{2}+\left(\mathrm{Y}_{\mathrm{CH} 1}-\mathrm{Y}_{\mathrm{n}}\right)^{2}}
$$

Here,

$\mathrm{dCH} 1_{\mathrm{n}}$ is the distance of $\mathrm{n}^{\text {th }}$ member from the Primary $\mathrm{CH}$. $X_{n}$ and $Y_{n}$ are the $X \& Y$ coordinates of the $n^{\text {th }}$ member. $\mathrm{X}_{\mathrm{CH} 1}$ and $\mathrm{Y}_{\mathrm{CH} 1}$ are the coordinates of the Primary $\mathrm{CH}$.
Mobility $\left(M_{n}\right)$ :

All the nodes in the MANET are mobile. It is always suitable to have the node less mobile to be a cluster head [2]. The distance traveled by a node in a given time can be used to determine mobility.

$$
M_{n}=\frac{1}{t_{2}-t_{1}} \sqrt{\left(X_{2}-X_{1}\right)^{2}+\left(Y_{2}-Y_{1}\right)^{2}}
$$

Here,

$t_{2}-t_{1}$ is the period under consideration.

$\mathrm{X}_{1}$ and $\mathrm{Y}_{1}$ are the coordinates at time $\mathrm{t}_{1}$

$\mathrm{X}_{2}$ and $\mathrm{Y}_{2}$ are the coordinates at time $\mathrm{t}_{2}$

Based on equations (1) and (2) from [2], we have derived the Robustness Factor $\left(\mathrm{RF}_{\mathrm{n}}\right)$ equation $(3)$, which is calculated for each node $\mathrm{n}$ as:

$$
\mathrm{RF}_{\mathrm{n}}=\alpha \cdot \mathrm{dCH} 1_{\mathrm{n}}+\beta \cdot\left(1-\mathrm{M}_{\mathrm{n}}\right)
$$

In equation (3), $\alpha$ and $\beta$ are the weight or importance factors assigned to distance and mobility respectively. The $\mathrm{dCH} 1_{\mathrm{n}}$ factor has a significant impact on the Secondary $\mathrm{CH}$ selection. It is observed that higher power is needed for higher distance communications. For the formation of a new cluster, it is preferable to give preference to distant nodes; the farther the distances of a node from the Primary Cluster Head, the more likely it is to be appointed as a new (i.e. Secondary) Cluster Head. A less mobile cluster head is a better candidate for Secondary Cluster Head as it gives the structure more stability.

The primary cluster head calculates the Robustness Factor $\left(R_{\mathrm{n}}\right)$ for all of its members and the node with the greatest value of Robustness Factor $\left(\mathrm{RF}_{\mathrm{n}}\right)$ is appointed as the Secondary $\mathrm{CH}$. Algorithm 3 presents the formation of the new cluster. Member nodes, which are closer to the newborn (i.e. secondary) cluster head than the primary cluster head comes in the affiliation of the secondary cluster head. The overload on the primary cluster head is significantly reduced when a new cluster is formed under the control of the secondary cluster head. As a result, the network's performance improves. 


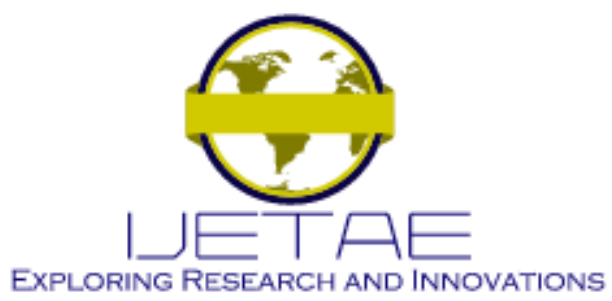

International Journal of Emerging Technology and Advanced Engineering

Website: www.ijetae.com (E-ISSN 2250-2459, Scopus Indexed, ISO 9001:2008 Certified Journal, Volume 11, Issue 08, August 2021)

Algorithm 3: Selection of Secondary Cluster head and Formation of Cluster

1. The Primary Cluster head $\mathrm{CH} 1$ of Cluster $\mathrm{C} 1$ repeatedly checks all the other member nodes of Cluster C1.

2. If (Number of members in Primary Cluster head

CH1 $>$ predefined Threshold value)

3. Then Primary Cluster head $\mathrm{CH} 1$ sends a "CLUSTER_PARTITION" signal to all its member nodes.

4. The Primary Cluster head CH1 computes the Robustness Factor $\left(\mathrm{RF}_{\mathrm{n}}\right)$ for all the member nodes and finds the node with the Greatest Robustness Factor $\left(\mathrm{RF}_{\mathrm{n}}\right)$.

5. The "CH_DESIGNATE" signal is sent by the Primary Cluster head $\mathrm{CH} 1$ to designate the node discovered in step 4 as a New Cluster head.

6. The node after receiving the "CH_DESIGNATE" signal declares itself as a Secondary Cluster head $\mathrm{CH} 3$ of Cluster $\mathrm{C} 1$ and also New Cluster C3 having Cluster head $\mathrm{CH} 3$ will be formed.

7. Now, Distance to each member node from the Primary Cluster head $\mathrm{CH} 1$ and Secondary Cluster head $\mathrm{CH} 3$ of the Cluster $\mathrm{C} 1$ will be calculated.

8. Let $\mathrm{dCH} 1 \mathrm{n}$ and $\mathrm{dCH} 3 \mathrm{n}$ be the distances between each node $\mathrm{n}$ and Cluster C1's Primary Cluster head $\mathrm{CH} 1$ and Secondary Cluster head $\mathrm{CH} 3$ respectively.

9. If $(\mathrm{dCH} 3 \mathrm{n}<\mathrm{dCH} 1 \mathrm{n})$

10. Then Secondary Cluster head CH3 sends a "join_cluster" message to such nodes.

11. These Nodes replies with "accept_join" and become the member of New Cluster C3.

else

12. Member Nodes must remain associated with the Cluster C1 having a Primary Cluster head CH1. else

13. No need for Cluster Partition.

The simulation of the proposed work on the network simulator as well as result analysis is described in the following sections of the paper.

\section{Simulation Results}

The Network Simulator (NS) is the most effective opensource software for simulating network events. This section provides an overview of the simulation environment as well as an analysis of the outcomes of simulations.
Table I

Simulation Parameters with its Environment

\begin{tabular}{|l|c|l|c|}
\hline Parameter & Value & Parameter & Value \\
\hline Simulator & NS 2.35 & $\begin{array}{l}\text { Radio } \\
\text { Propagation } \\
\text { Model }\end{array}$ & Two Ray Ground \\
\hline $\begin{array}{l}\text { MAC } \\
\text { Type }\end{array}$ & 802.11 & $\begin{array}{l}\text { Traffic } \\
\text { Type }\end{array}$ & CBR (UDP) \\
\hline $\begin{array}{l}\text { Simulation } \\
\text { Area }\end{array}$ & $\begin{array}{l}800 \mathrm{~m} \mathrm{X} \\
600 \mathrm{~m}\end{array}$ & $\begin{array}{l}\text { Data } \\
\text { Payload }\end{array}$ & 128 bytes/packet \\
\hline $\begin{array}{l}\text { Simulation } \\
\text { Time }\end{array}$ & $100 \mathrm{sec}$ & $\begin{array}{l}\text { Packet } \\
\text { Interval }\end{array}$ & $\begin{array}{l}0.033,0.04,0.066, \\
0.2,0.1,1 \mathrm{~s}\end{array}$ \\
\hline $\begin{array}{l}\text { Number of } \\
\text { Nodes }\end{array}$ & 30 & $\begin{array}{l}\text { Antenna } \\
\text { Type }\end{array}$ & Omni-Antenna \\
\hline $\begin{array}{l}\text { Channel } \\
\text { Type }\end{array}$ & Wireless & $\begin{array}{l}\text { Mobility } \\
\text { Model }\end{array}$ & Random Waypoint \\
\hline
\end{tabular}

The "Cluster Formation and Maintenance Techniques for Mobile Adhoc Networks with Improved Quality of Service (CFMIQS)" are performed in the proposed work. The network structure in the event of cluster maintenance is explained in the following three scenarios.

In these scenarios, we are considering the K-means clustering algorithm.

The K-means clustering algorithm is used to cluster nodes based on the Partitioning approach of clustering. The main purpose of this clustering is to partition $\mathrm{n}$ nodes into $\mathrm{K}$ clusters. Here, $\mathrm{K}$ signifies the number of clusters.

$K$-means algorithm is implemented in 3 steps:

Initial clustering: Every network node is allocated to one of the $\mathrm{K}$ clusters. The $\mathrm{K}$ Cluster heads are chosen. Using the Euclidean distance formula, the other member nodes determine which $\mathrm{CH}$ is closest to it.

Re-clustering: Here, each cluster's centroid is calculated. This step is recursively repeated in each cluster with the new $\mathrm{CH}$ until the $\mathrm{CH}$ is no longer changed.

Choosing the $\mathrm{CH}$ : After clusters are formed, each node is assigned an ID number based on its distance from the centroid. The closer node received a lower number. The ID number determines the order in which a node's ID number is assigned as the $\mathrm{CH}$.

AODV (Adhoc On-demand Distance Vector) is a reactive protocol that only finds routes to specific destinations when they are required. Routes are created ondemand in AODV, and destination sequence numbers are used to locate the most recent route to the destination. 


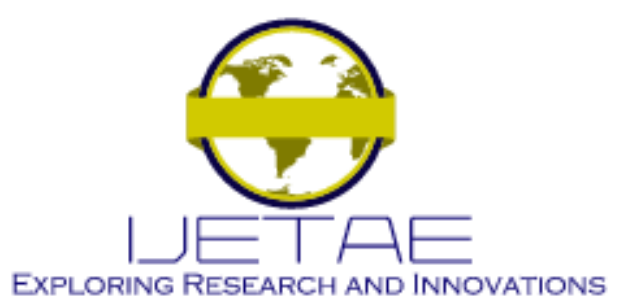

International Journal of Emerging Technology and Advanced Engineering

Website: www.ijetae.com (E-ISSN 2250-2459, Scopus Indexed, ISO 9001:2008 Certified Journal, Volume 11, Issue 08, August 2021)

By combining K-means clustering with AODV routing the routes in the network can be found.

\section{AMember Node Movement (Scenario 1)}

Figure 4 depicts a network of 30 mobile nodes randomly distributed over an area. This network is partitioned into clusters using K-means with randomly selected centroids mostly in a vertical manner, as shown in Figure 5. The procedure for selecting the cluster head is applied to the clusters after they have been formed. The $\mathrm{K}$ number of cluster heads is taken as the $\mathrm{K}$ number of $\mathrm{K}$-centroids formed using the $\mathrm{K}$-means algorithm in this method, as shown by arrows in Figure 6. Initially, in the Simulation process, we keep the Number of Clusters as 3.

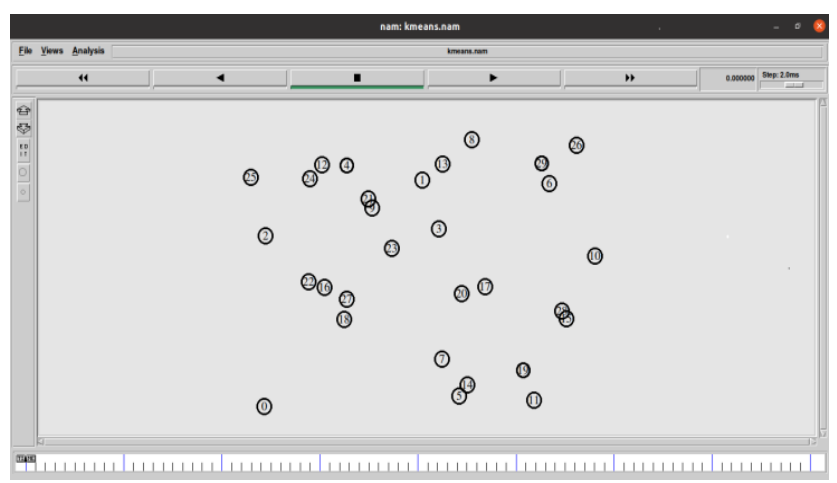

Figure 4. Network with 30 Mobile Nodes

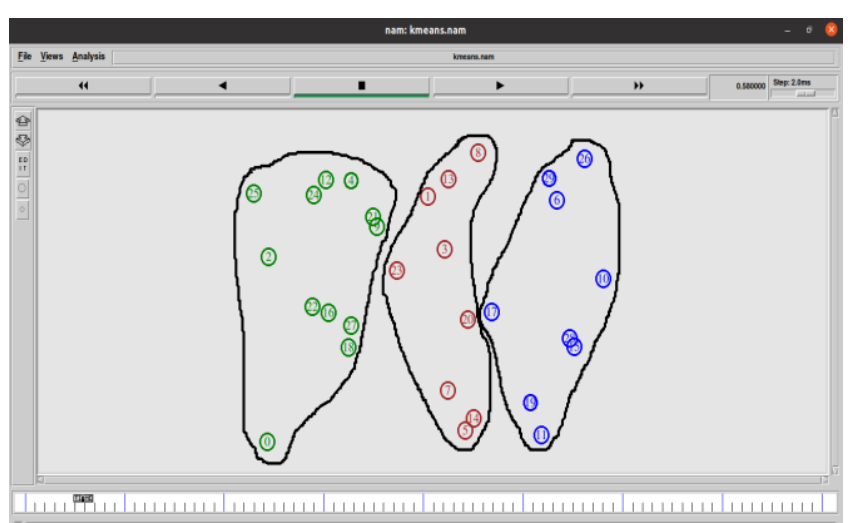

Figure 5. Nodes are grouped into 3 Clusters shown in Green, Brown and Blue colors

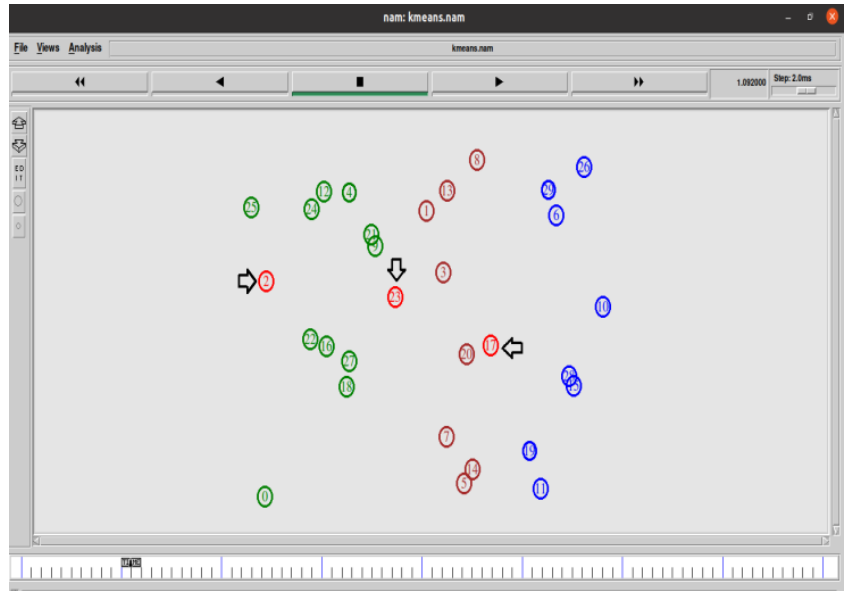

Figure 6. Cluster heads are identified by arrows in Red color

As part of the Cluster Maintenance in the case of Member Node movement Figure 7 shows that Node label 0 by an arrow is moving away from the group of cluster nodes displayed in 'Green' color. After some time, Node label 0 joined the group of cluster nodes displayed in 'Brown' color, which is shown by an arrow in Figure 8.

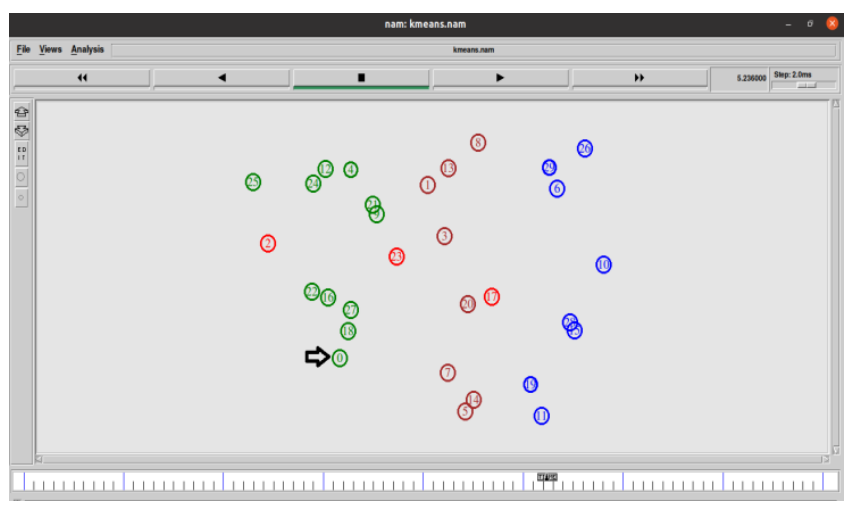

Figure 7. Node label 0 is moving away from the Green color cluster 


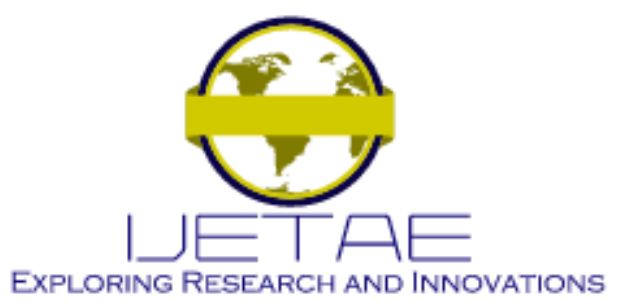

International Journal of Emerging Technology and Advanced Engineering Website: www.ijetae.com (E-ISSN 2250-2459, Scopus Indexed, ISO 9001:2008 Certified Journal, Volume 11, Issue 08, August 2021)

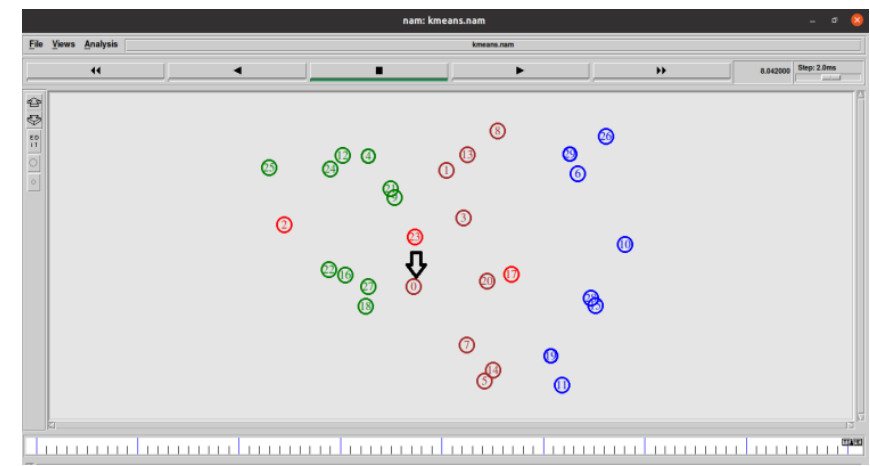

Figure 8. Node label 0 joined the Brown color cluster

\section{B Cluster head Node Movement (Scenario 2)}

Figure 9 represents a network of 30 mobile nodes distributed across a large area. This network is divided into clusters using K-means with centroids chosen at random, as shown in Figure 10. The method for identifying the cluster head is extended to the clusters after they have been created. The $\mathrm{K}$ number of cluster heads equals the $\mathrm{K}$ number of K-centroids generated using the K-means algorithm, as shown by arrows in Figure 11. Initially, in the Simulation process, we keep the Number of Clusters as 3.

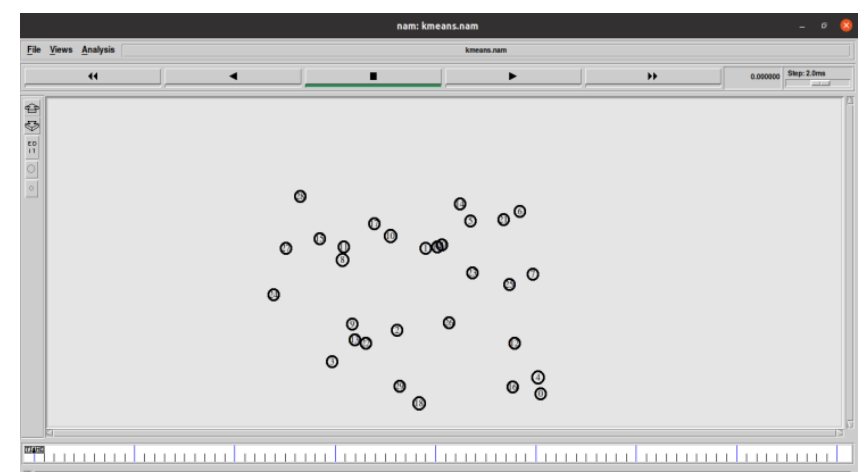

Figure 9. Network with 30 Mobile Nodes

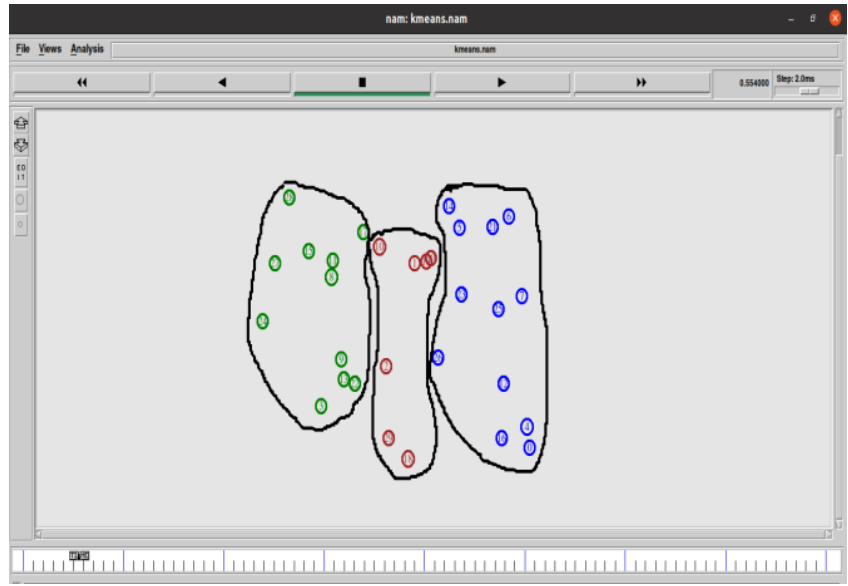

Figure 10. Nodes are grouped into 3 Clusters shown in Green, Brown and Blue colors

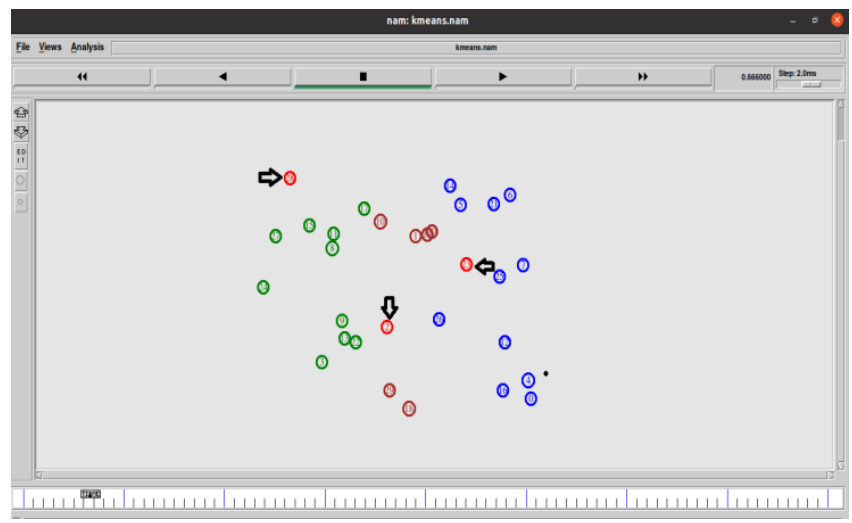

Figure 11. Cluster heads are identified by arrows in Red color

Figure 12 and Figure 13 show that Cluster head Node label 23 is moving away from the group of cluster nodes displayed in 'Blue' color. When the Cluster head Node label 23 has moved too far away from the group of cluster nodes represented in the 'Blue' color, a new Cluster head must be selected among the remaining cluster member nodes. Figure 14 shows that from the group of cluster nodes displayed in the 'Blue' color, Node label 26 is selected as a New Cluster head. 


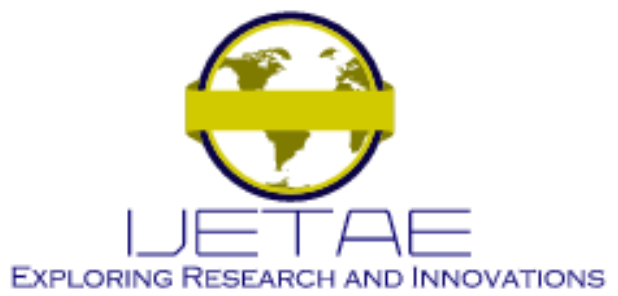

International Journal of Emerging Technology and Advanced Engineering

Website: www.ijetae.com (E-ISSN 2250-2459, Scopus Indexed, ISO 9001:2008 Certified Journal, Volume 11, Issue 08, August 2021)

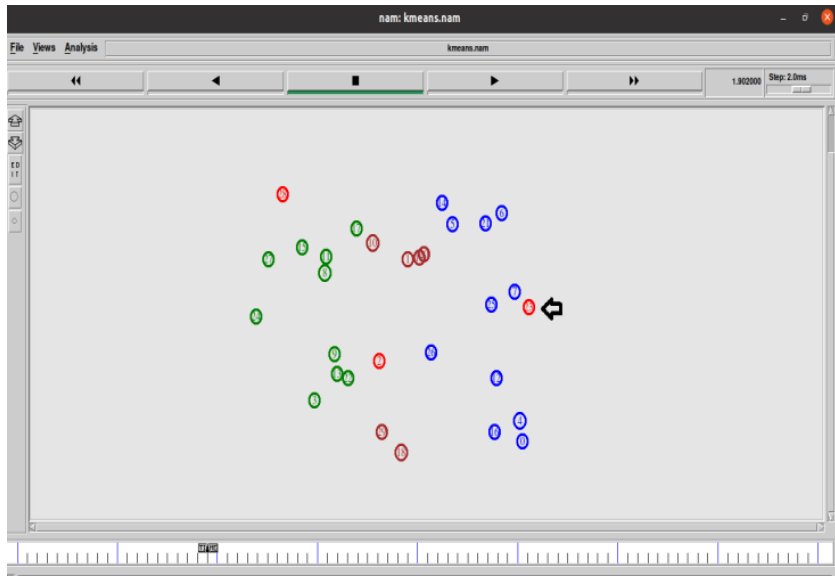

Figure 12. Cluster head Node label 23 is moving away from the Blue color cluster

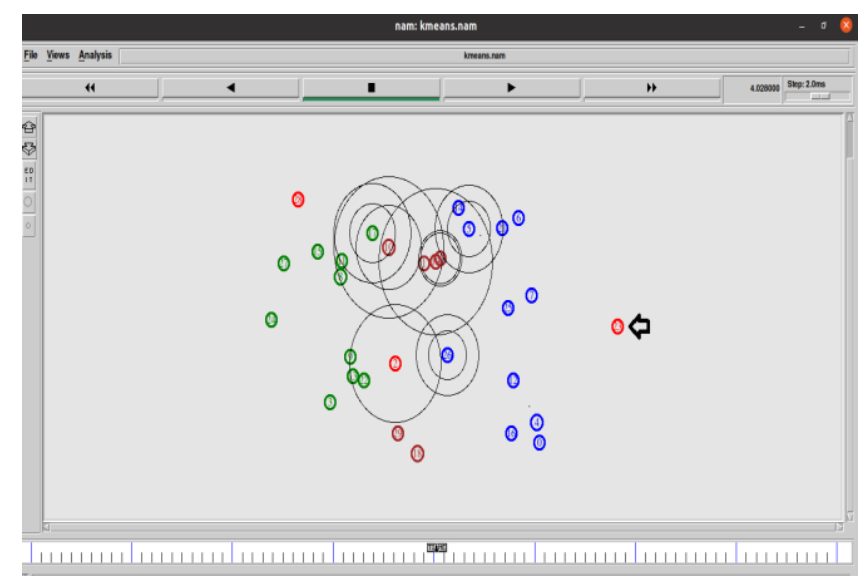

Figure 13. Cluster head Node label 23 has moved too far away from the Blue color cluster

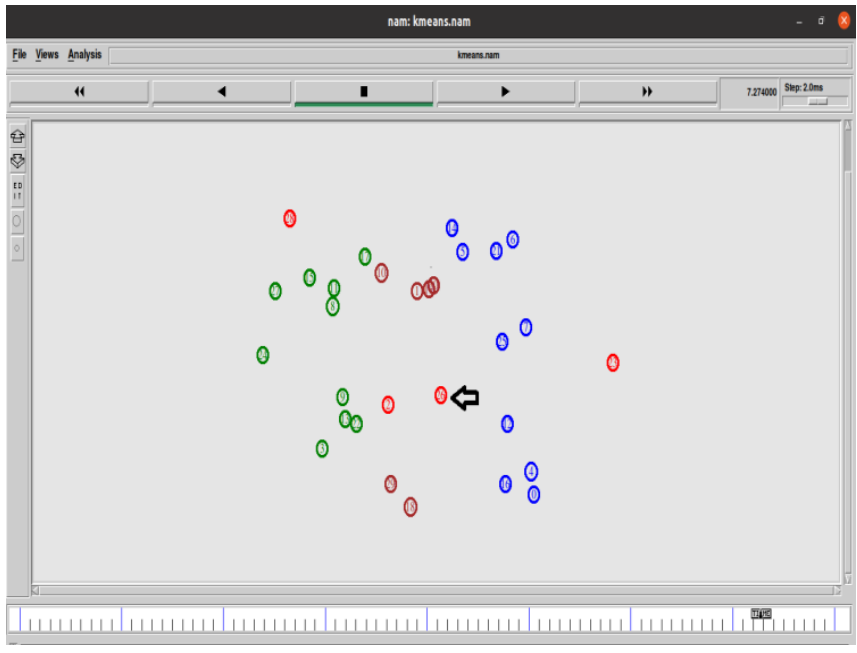

Figure 14. Another Node (i.e. Node label 26) from the Blue color cluster was selected as a New Cluster head

IV. C Overload at Cluster head node (Scenario 3)

Figure 15 describes a network of 30 mobile nodes scattered across a large area. Initially, in the Simulation process, we keep the Number of Clusters as 3. This can be shown in Figure 16 by the three clusters namely Green, Brown, and Blue colors. After cluster formation, its cluster head is identified. This is shown in Figure 17 by arrows.

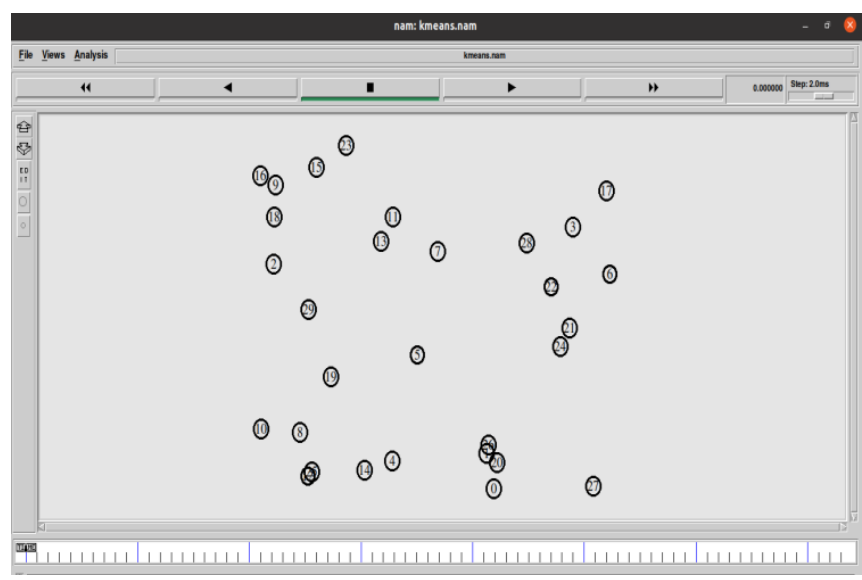

Figure 15. Network with 30 Mobile Nodes 


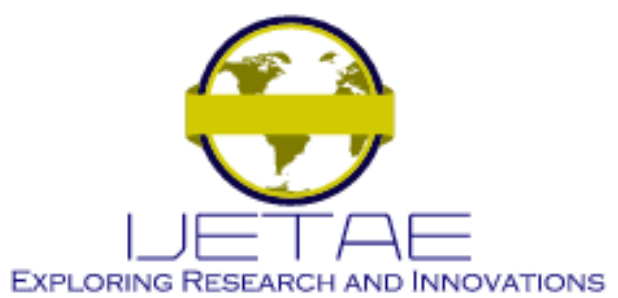

International Journal of Emerging Technology and Advanced Engineering

Website: www.ijetae.com (E-ISSN 2250-2459, Scopus Indexed, ISO 9001:2008 Certified Journal, Volume 11, Issue 08, August 2021)

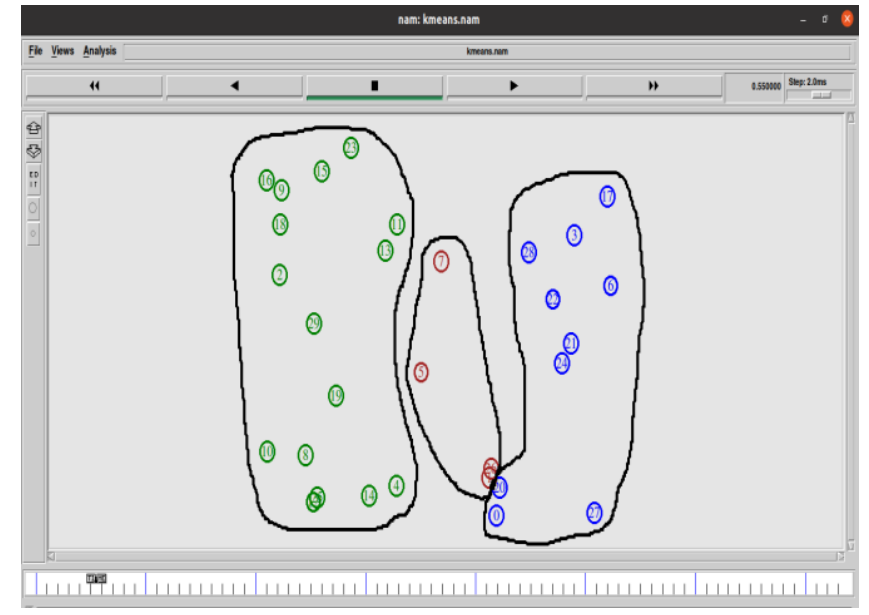

Figure 16. Nodes are grouped into 3 Clusters shown in Green, Brown and Blue colors

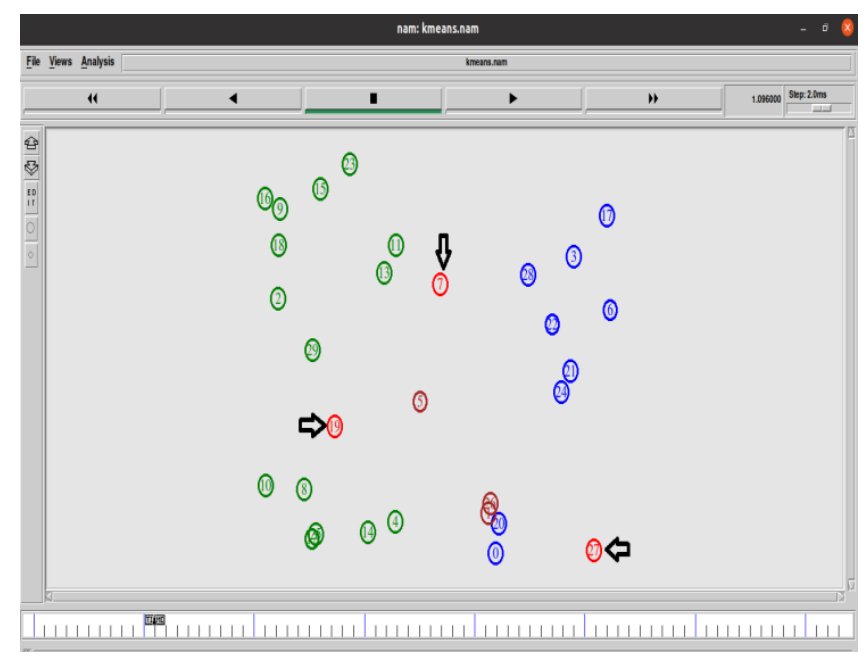

Figure 17. Cluster heads are identified by arrows in Red color

The Cluster is eligible for partition when the Primary Cluster head holds the member nodes greater than the predefined threshold value. Then, in this case, the Cluster will choose the Secondary Cluster head from among the member nodes with the highest Robustness Factor $\left(\mathrm{RF}_{\mathrm{n}}\right)$ from the Primary Cluster head.

Figure 18 shows that the 'Green' color cluster is partitioned and from that, a new Secondary Cluster head node label 23 is chosen to have already existing Primary Cluster head node label 19.

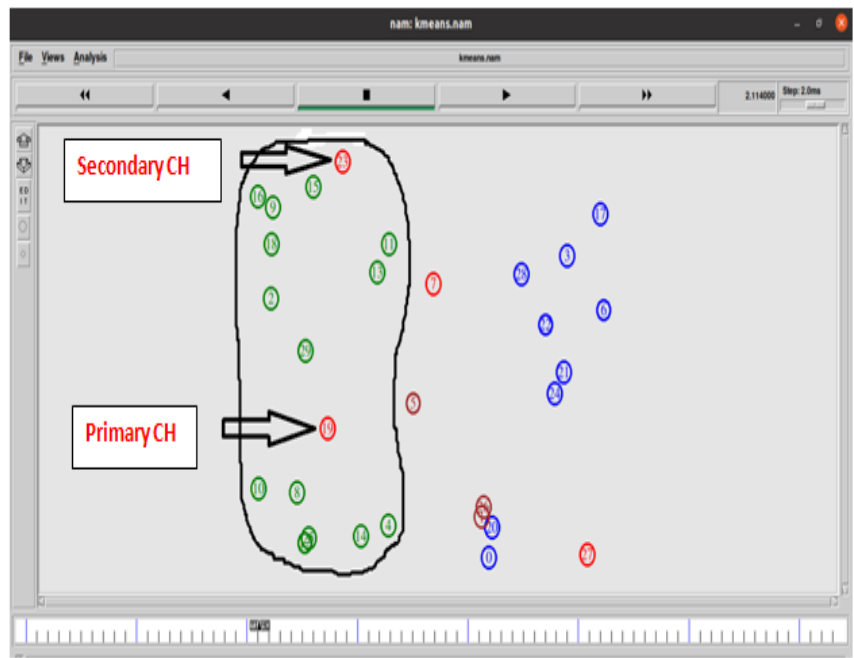

Figure 18. Green Cluster is partitioned and a New Secondary Cluster head is chosen as Node label 23

The distance of each member node from the Cluster's Primary as well as Secondary Cluster heads will now be calculated. The New Cluster will include the member nodes closer to the Secondary $\mathrm{CH}$, with the Secondary $\mathrm{CH}$ taking over the Primary Cluster head's responsibilities.

Figure 19 shows that nodes closer to the New Secondary Cluster head node label 23 have joined as member nodes of the New Cluster formed. Now, the number of clusters increases from 3 to 4 . This new cluster is shown in the 'Purple' color.

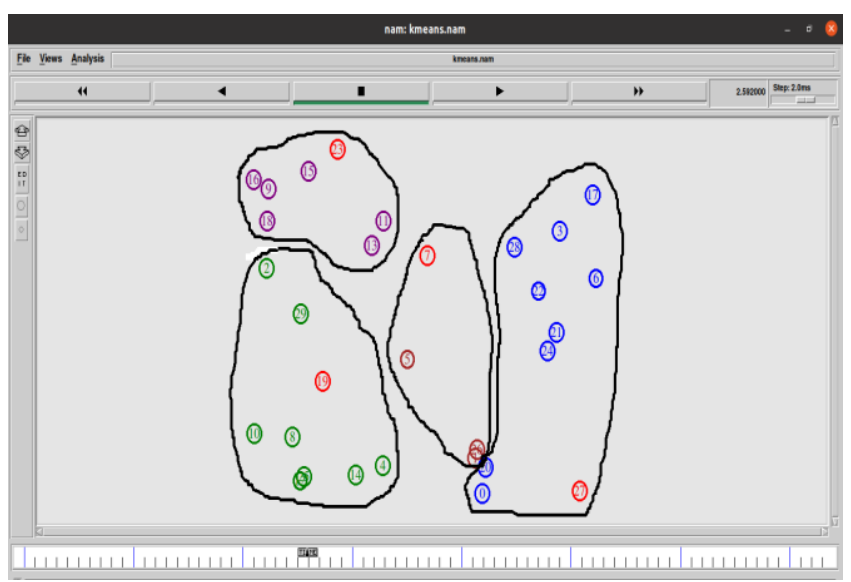

Figure 19. Nodes closer to Secondary Cluster head Node label 23 joined as Cluster Member Nodes 


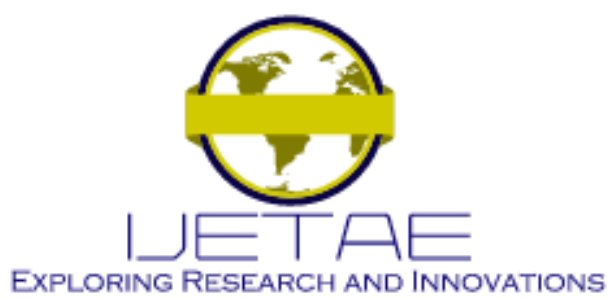

International Journal of Emerging Technology and Advanced Engineering Website: www.ijetae.com (E-ISSN 2250-2459, Scopus Indexed, ISO 9001:2008 Certified Journal, Volume 11, Issue 08, August 2021)

When the cluster head of the cluster shown in the 'Blue' color is overloaded (i.e. having member nodes more than the predefined threshold value) as displayed in Figure 19. Then, this cluster is eligible for partition and it is partitioned into smaller clusters, namely the clusters shown in 'Blue' and 'Violet' colors. Now, the number of clusters increases from 4 to 5 as shown in Figure 20.

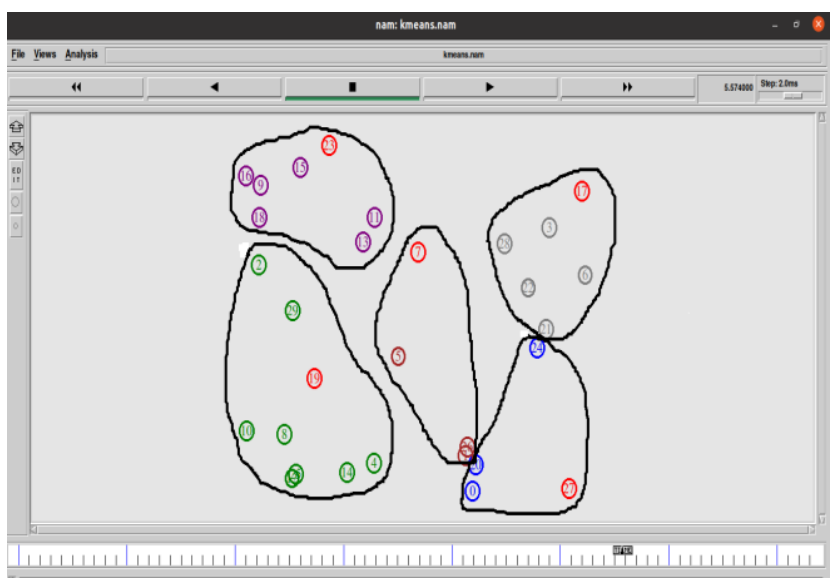

Figure 20. Partitioned the Blue Cluster after overloaded into Blue and Violet color clusters

\section{RESUlt ANALYSIS}

As the NS2 Simulation result will be outputted to out.tr file and out.nam file. The file out.tr includes a record for every packet arrival, queue event, and departure, whereas file out.nam used by the Network Animator (NAM), which allows packets movement through visual display. Figure 21 indicates packets transmission between nodes $(0-2),(1-2)$, and $(2-3)$.

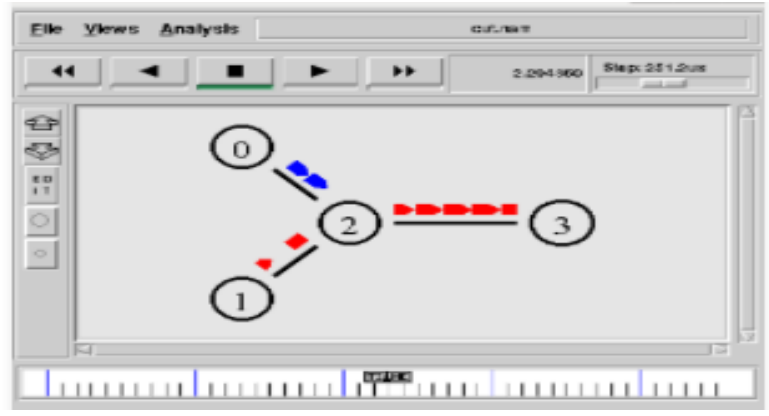

Figure 21. Packets transmission between nodes
Here, the mechanism used for communication is CBR (UDP). The term Constant Bit Rate (CBR) refers to the QoS in telecommunications. This encoding specifies a constant rate of consumption of data packets. The User Datagram Protocol (UDP) is mainly used for establishing connection-less communication.

This section compares and analyses the results of $\mathrm{K}$ means AODV and CFMIQS Scenarios 1, 2, and 3. In terms of PDF and Throughput, we are comparing and analyzing them.

Table II

PDF for K-means AODV and Scenario 1 of CFMIQS

\begin{tabular}{|c|c|c|c|}
\hline S.No. & $\begin{array}{c}\text { Number of Packets } \\
\text { sent at regular } \\
\text { intervals }\end{array}$ & $\begin{array}{c}\text { PDF for } \\
\text { K-means } \\
\text { AODV }\end{array}$ & $\begin{array}{c}\text { PDF for } \\
\text { Scenario 1 of } \\
\text { CFMIQS }\end{array}$ \\
\hline 1. & 1 & 70.14 & 87.03 \\
\hline 2. & 5 & 68.90 & 84.28 \\
\hline 3. & 10 & 68.31 & 83.59 \\
\hline 4. & 15 & 66.79 & 81.84 \\
\hline 5. & 25 & 63.57 & 77.37 \\
\hline 6. & 30 & 62.84 & 75.91 \\
\hline
\end{tabular}

Table II shows the PDF comparison of the K-means AODV and CFMIQS Scenario 1 in terms of packets sent at regular intervals. From Figure 22 we infer that the technique proposed in CFMIQS Scenario 1 is better than the K-means AODV.

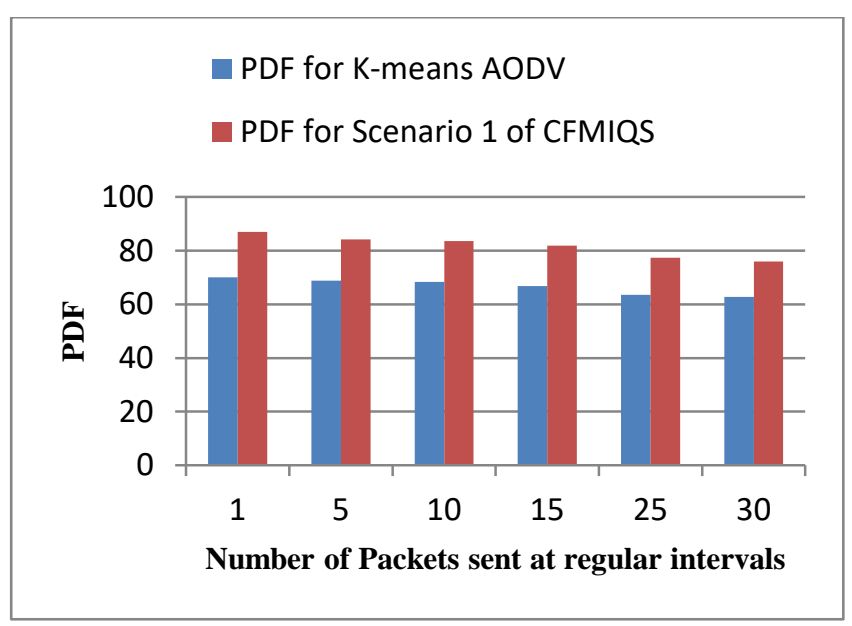

Figure 22. PDF v/s Number of Packets sent at regular intervals 


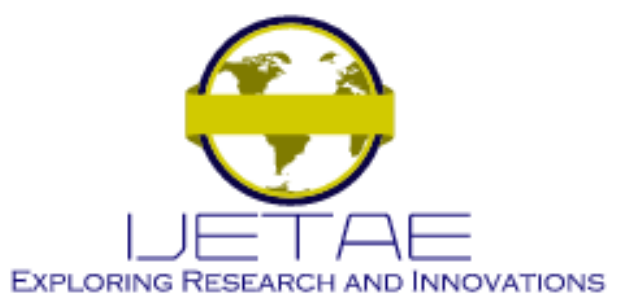

International Journal of Emerging Technology and Advanced Engineering

Website: www.ijetae.com (E-ISSN 2250-2459, Scopus Indexed, ISO 9001:2008 Certified Journal, Volume 11, Issue 08, August 2021)

Table III

PDF for K-means AODV and Scenario 2 of CFMIQS

\begin{tabular}{|c|c|c|c|}
\hline S.No. & $\begin{array}{c}\text { Number of Packets } \\
\text { sent at regular } \\
\text { intervals }\end{array}$ & $\begin{array}{c}\text { PDF for } \\
\text { K-means } \\
\text { AODV }\end{array}$ & $\begin{array}{c}\text { PDF for } \\
\text { Scenario 2 of } \\
\text { CFMIQS }\end{array}$ \\
\hline 1. & 1 & 70.14 & 89.09 \\
\hline 2. & 5 & 68.90 & 87.98 \\
\hline 3. & 10 & 68.31 & 87.01 \\
\hline 4. & 15 & 66.79 & 86.48 \\
\hline 5. & 25 & 63.57 & 83.51 \\
\hline 6. & 30 & 62.84 & 81.95 \\
\hline
\end{tabular}

Table III shows the PDF comparison of the K-means AODV and CFMIQS Scenario 2 in terms of packets sent at regular intervals. From Figure 23 we infer that the technique proposed in CFMIQS Scenario 2 is better than the K-means AODV.

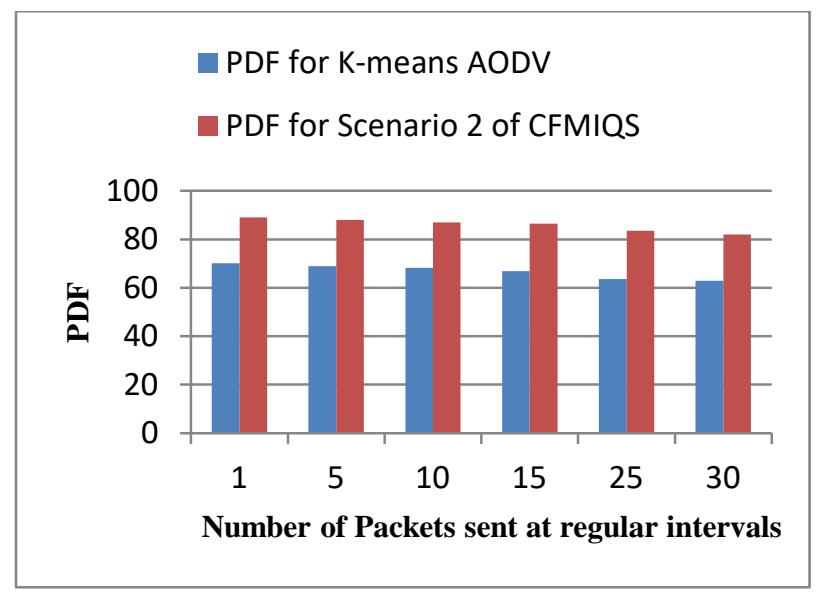

Figure 23. PDF v/s Number of Packets sent at regular intervals

Table IV

PDF for K-means AODV and Scenario 3 of CFMIQS

\begin{tabular}{|c|c|c|c|}
\hline S.No. & $\begin{array}{c}\text { Number of Packets } \\
\text { sent at regular } \\
\text { intervals }\end{array}$ & $\begin{array}{c}\text { PDF for } \\
\text { K-means } \\
\text { AODV }\end{array}$ & $\begin{array}{c}\text { PDF for } \\
\text { Scenario 3 of } \\
\text { CFMIQS }\end{array}$ \\
\hline 1. & 1 & 70.14 & 92.35 \\
\hline 2. & 5 & 68.90 & 91.96 \\
\hline 3. & 10 & 68.31 & 88.44 \\
\hline 4. & 15 & 66.79 & 87.40 \\
\hline 5. & 25 & 63.57 & 84.37 \\
\hline 6. & 30 & 62.84 & 82.74 \\
\hline
\end{tabular}

Table IV shows the PDF comparison of the K-means AODV and CFMIQS Scenario 3 in terms of packets sent at regular intervals. From Figure 24 we infer that the technique proposed in CFMIQS Scenario 3 is better than the K-means AODV.

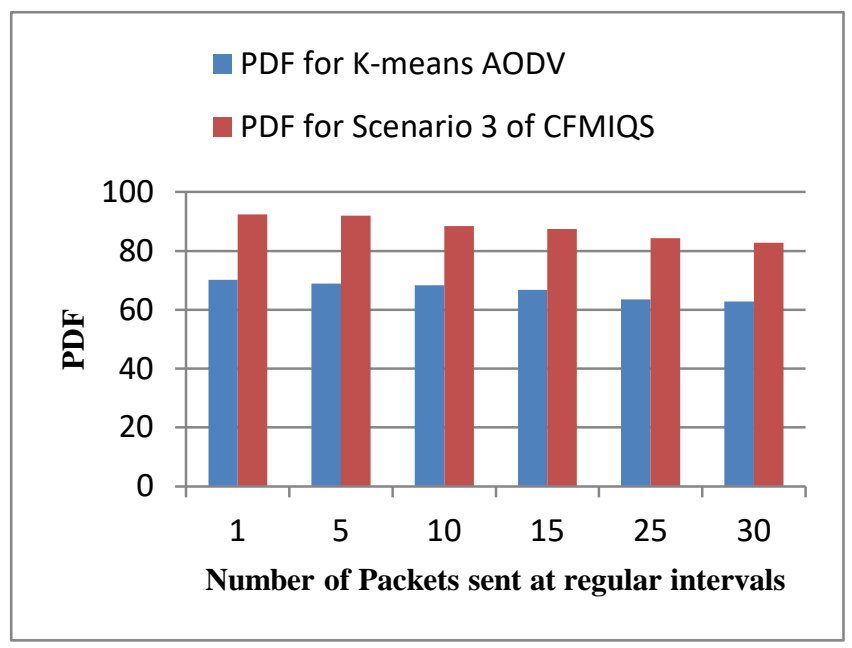

Figure 24. PDF v/s Number of Packets sent at regular intervals

Table V

Throughput for K-means AODV and Scenario 1 of CFMIQS

\begin{tabular}{|c|c|c|c|}
\hline S.No. & $\begin{array}{c}\text { Number of } \\
\text { Packets sent at } \\
\text { regular intervals }\end{array}$ & $\begin{array}{c}\text { Throughput } \\
\text { for K-means } \\
\text { AODV }\end{array}$ & $\begin{array}{c}\text { Throughput } \\
\text { for Scenario 1 } \\
\text { of CFMIQS }\end{array}$ \\
\hline 1. & 1 & 715.31 & 803.85 \\
\hline 2. & 5 & 748.94 & 835.83 \\
\hline 3. & 10 & 781.13 & 874.86 \\
\hline 4. & 15 & 791.36 & 892.53 \\
\hline 5. & 25 & 805.84 & 930.37 \\
\hline 6. & 30 & 814.53 & 953.25 \\
\hline
\end{tabular}

Table V displays the Throughput comparison of the $\mathrm{K}$ means AODV and CFMIQS Scenario 1 in terms of packets sent at regular intervals. From Figure 25 we infer that the technique proposed in CFMIQS Scenario 1 is better than the K-means AODV. 


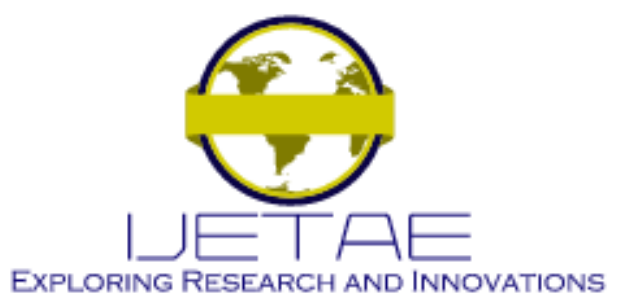

International Journal of Emerging Technology and Advanced Engineering Website: www.ijetae.com (E-ISSN 2250-2459, Scopus Indexed, ISO 9001:2008 Certified Journal, Volume 11, Issue 08, August 2021)

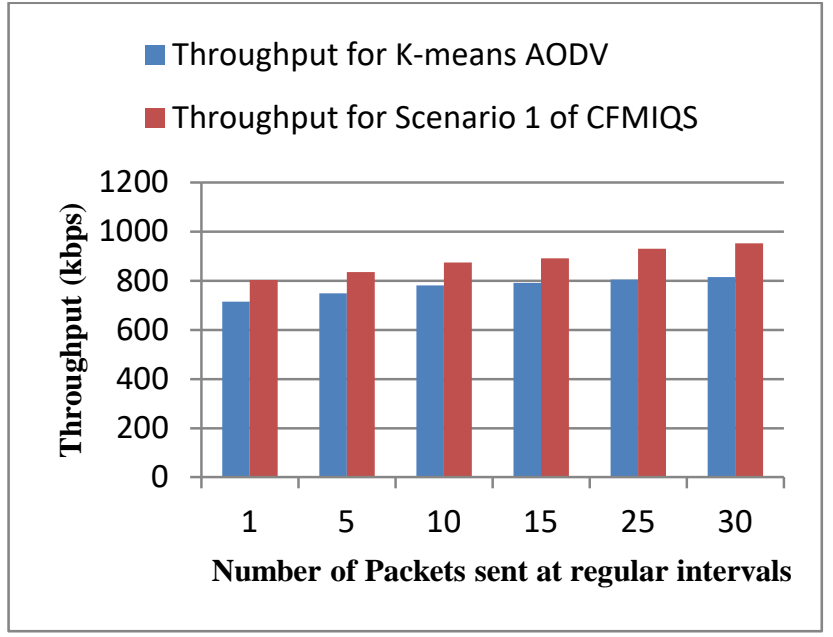

Figure 25. Throughput v/s Number of Packets sent at regular intervals

Table VI

Throughput for K-means AODV and Scenario 2 of CF MIQS

\begin{tabular}{|c|c|c|c|}
\hline S.No. & $\begin{array}{c}\text { Number of } \\
\text { Packets sent at } \\
\text { regular intervals }\end{array}$ & $\begin{array}{c}\text { Throughput } \\
\text { for K-means } \\
\text { AODV }\end{array}$ & $\begin{array}{c}\text { Throughput } \\
\text { for Scenario 2 } \\
\text { of CFMIQS }\end{array}$ \\
\hline 1. & 1 & 715.31 & 826.27 \\
\hline 2. & 5 & 748.94 & 858.82 \\
\hline 3. & 10 & 781.13 & 893.17 \\
\hline 4. & 15 & 791.36 & 908.53 \\
\hline 5. & 25 & 805.84 & 951.28 \\
\hline 6. & 30 & 814.53 & 977.32 \\
\hline
\end{tabular}

Table VI displays the Throughput comparison of the Kmeans AODV and CFMIQS Scenario 2 in terms of packets sent at regular intervals. From Figure 26 we infer that the technique proposed in CFMIQS Scenario 2 is better than the K-means AODV.

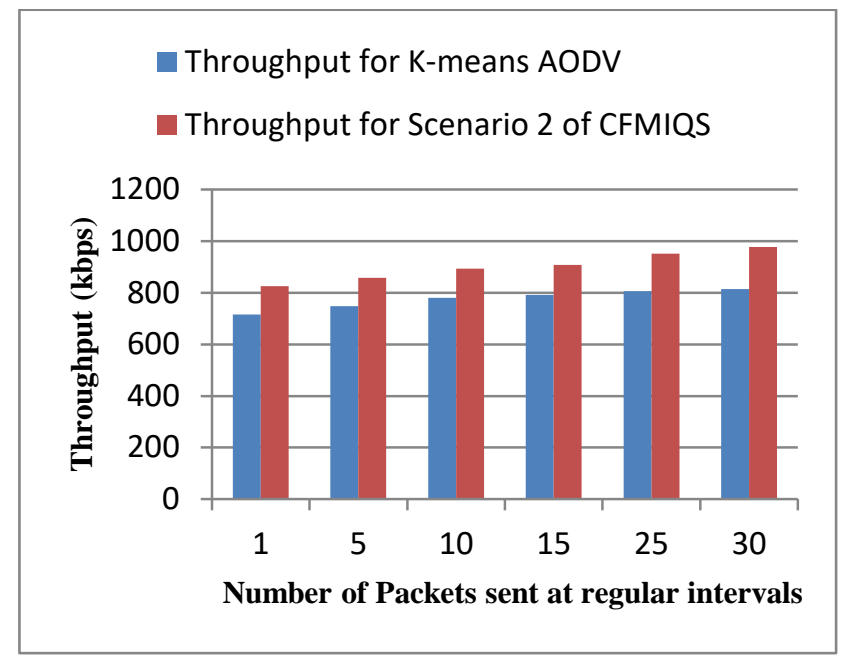

Figure 26. Throughput v/s Number of Packets sent at regular intervals

Table VII

Throughput for K-means AODV and Scenario 3 of CF M IQS

\begin{tabular}{|c|c|c|c|}
\hline S.No. & $\begin{array}{c}\text { Number of } \\
\text { Packets sent at } \\
\text { regular intervals }\end{array}$ & $\begin{array}{c}\text { Throughput } \\
\text { for K-means } \\
\text { AODV }\end{array}$ & $\begin{array}{c}\text { Throughput } \\
\text { for Scenario 3 } \\
\text { of CFMIQS }\end{array}$ \\
\hline 1. & 1 & 715.31 & 851.83 \\
\hline 2. & 5 & 748.94 & 885.14 \\
\hline 3. & 10 & 781.13 & 925.02 \\
\hline 4. & 15 & 791.36 & 958.07 \\
\hline 5. & 25 & 805.84 & 1002.45 \\
\hline 6. & 30 & 814.53 & 1037.78 \\
\hline
\end{tabular}

Table VII displays the Throughput comparison of the Kmeans AODV and CFMIQS Scenario 3 in terms of packets sent at regular intervals. From Figure 27 we infer that the technique proposed in CFMIQS Scenario 3 is better than the K-means AODV. 


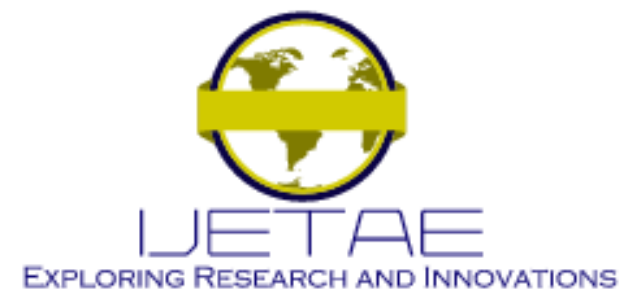

International Journal of Emerging Technology and Advanced Engineering Website: www.ijetae.com (E-ISSN 2250-2459, Scopus Indexed, ISO 9001:2008 Certified Journal, Volume 11, Issue 08, August 2021)

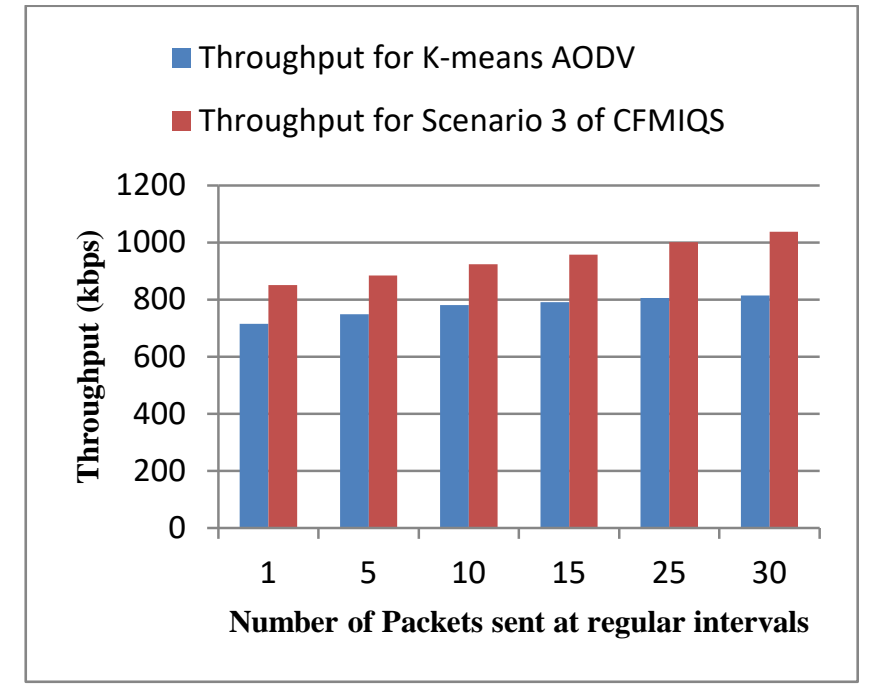

Figure 27. Throughput v/s Number of Packets sent at regular intervals

\section{CONCLUSION}

We have proposed a new method for cluster formation and its maintenance to resolve some network issues caused due to the mobility of nodes. System simulations confirm that the proposed method Cluster Formation and Maintenance Techniques for Mobile Adhoc Networks with Improved Quality of Service (CFMIQS), which consists of three scenarios to deal with three major network issues, greatly increases the PDF and Throughput of the System. It performs better than the K-means AODV. By improving the network's performance in terms of PDF and Throughput, this method provides QoS to the network.

\section{REFERENCES}

[1] R. Agarwal, M. Motwani, and R. Gupta, "A Framework for Load Sharing in Clustered Adhoc Networks", International Journal of Computer Application, Volume 78, Issue 8, September 2013, pp. 3137.

[2] M. Chatterjee, S. Das, and D. Turgut, "WCA: A weighted clustering algorithm for mobile ad hoc networks", Cluster Computing Journal, Volume 5, Issue 2, 2002, pp. 193-204.
[3] B.A. Kumar, M.V. Subramanyam, and K. S. Prasad, "An Energy Efficient Clustering using KMeans and AODV Routing Protocol in Ad-hoc Networks", International Journal of Intelligent Engineering \& Systems, Volume 12, Issue 2, 2019, pp. 125-134.

[4] M.Vijayalakshmi, and D.S. Rao, "Energy Aware Multicast Clustering (EAMC) with increased Quality of Service (QoS) in MANETs", 2nd International Conference on Applied and Theoretical Computing and Communication Technology (iCATccT), 2016, pp. 793-798.

[5] J. O. Jejeniwa, and R. A. Uthra, "Dual Head Cluster: A Single Cluster Environment for Large-Scale Mobile Adhoc Networks", International Journal of Scientific \& Engineering Research, Volume 5, Issue 5, May 2014, pp. 565-569.

[6] N. Rajendran, and E.R. Naganathan, "Collaborative Opportunistic Zone Division Clustering and Routing Algorithm for Congestion Control and Load Balancing on MANET", International Journal of Advanced Research in Engineering and Technology (IJARET), Volume 11, Issue 10, October 2020, pp. 1111-1120.

[7] S. Aruna, and A. Subramani, "Security Enhanced Weighted Double Cluster Head based Routing Scheme for Efficient Routing in MANETs", International Journal of Scientific \& Engineering Research, Volume 6, Issue 4, April-2015, pp. 274-279.

[8] V. B. Vieu, H.Benaboud, and N. Mikou, "MPWCA-L: A New Clustering Algorithm to Improve Stability and QoS in MANETs", International Journal of Simulation Systems, Science \& Technology, Volume 14, Issue 5, October 2013, pp. 1-10.

[9] K. S. Sowmya, and N. K. Cauvery, "Weighted Clustering Algorithm with Ant Colony Optimization to Provide Better Quality of Service”, International Journal of Computer Science and Information Technologies (IJCSIT), Volume 5, Issue 6, 2014, pp. 7702-7705.

[10] P. Dixit, A. Pillai, and R. Rishi, "A light weight efficient cluster based routing model for mobile adhoc networks (LWECM)", International Journal of Information Technology (IJIT), Volume 11, Issue 1, January 2019.

[11] L. Wang, and S. Olariu, "Cluster Maintenance in Mobile Adhoc Networks", Cluster Computing, Volume 8, Issue 2-3, 2005, pp. 111118.

[12] S. Pathak, N. Dutta, and S. Jain, “An Improved Cluster Maintenance Scheme for Mobile Adhoc Networks", International Conference on Advances in Computing, Communications and Informatics (ICACCI), 2014, pp. 2117-2121.

[13] K. A. Yitayih, and M. Libsie, "Towards Developing Enhanced Cluster-Based QoS-Aware Routing in MANET", Journal of Computer Networks and Communications, Volume 20, Issue 20, 2020, pp. 1-10.

[14] H. G. Kidanu, and P. Setty, "Distance Based Cluster Formation for Enhancing the Network Lifetime in MANETS", International Research Journal of Engineering and Technology (IRJET), Volume 4, Issue 10, October 2017, pp. 844-849. 